\title{
Exploring Corporate Strategic Management and Global Expansion on the Case study of Samsung Electronics
}

\author{
Ibrahim Mussa Haroun \\ Strategic Management \\ Email ibramussa@yahoo.com
}

\begin{abstract}
Basically, to offset any potential future concerns the organizations must be embedded with sustainable strategies which could restore the organization's reputation as well as competitive advantage. In the 21st century however, many organizations have grown hot with the ideology and so working hard to formulate strategies which could potentially keep them stay in the business and achieve their intended goals and objectives. Perhaps even more significantly, to achieve their strategic move, many of these organizations have opted to go global. This piece of research however, intends to investigate on the concept of "Assembling the Global Enterprise" whereby the report will be produced based on the "Samsung Electronics" where the adaptation of context, theories, models and tools containing within the strategic management become and appears to be the central part of the theme.
\end{abstract}

\section{INTRODUCTION}

Basically, Samsung Electronics is one of the major electronics multinational organizations in the world. The firm headquarter has been located in Suwon South Korea. It has been originated as Samsung Group subsidiary in 1969 and become global largest information Technology Company in terms of financial performance since 2009. Most importantly, Samsung Electronics has assembly plant network in 88 countries and indeed employs more than 370,000 people around the world. However, Samsung Electronics has been major manufacturer of electronics devices such as hard drive, semiconductor, and flash memory and become big suppliers of electronics company client such as Sony, HTC, Apple and Nokia. However, most recently, the firm has been diversified in consumer electronics and become biggest mobiles and smart phones producer around the globe which is fuelled by the popularity of Samsung Galaxy. The firm also popular vendor of product such as tablet computers such as android powers Samsung galaxy as well as Samsung galaxy note.

Indeed, in 1969 -1987 sine the firm has been established, its early products based on the electronics appliances such as television, calculators, refrigerators, air conditions and washing machines. In 1970 however, Samsung Group launch another subsidiary known as SamsungNEC which is jointly working with Japan's NEC Corporation to produce and manufacture audiovisual and home appliance devices. In 1974 however, the firm has potentially expanded into semi-conductors products by acquiring Korea semi-conductors and also acquired Korea Telecommunication base on electronic switching producers.

Moreover, in 1988-1995, the firm launched its first mobile phone in 1988. However, the performance was poor as $60 \%$ of the mobile market share was controlled by Motorola while Samsung controlled only 10\%. The major reason for under performance was poor quality which led to inferior product and during the mid 1990s become the biggest headlines for the 
firm to exit the business until the firm acquired 40\% stake in AST research- the US computer personnel maker for \$378 millions in February 1995. However, in 1995-2008 there was a need of great strategic change due to poor performance and the need to become leading technology producing company. To achieve this however, the firm used vertical integration strategy and by 2000 s the firm was able to produce several equipments. Indeed, brand awareness and image was developed when Samsung sponsored sports events such as Olympic event held in Nagano, Japan 1998. However, after concentrating on technology rather than the products, Samsung made remarkable breakthrough in technology particularly in the field of memory chip which is very common in electric market today including first 64Mb DRAM in 1992, 256 DRAM in 1994, 1 Gb DRAM in 1996, and in 2005 Samsung developed world first 8 Gb NAND memory and supplied to Apple and become the main supplier of Apple components such as A7 processor which currently available in Apple I Phone 5s.

On the other hand, from 2008 to present Samsung performance has been outstanding where in 2005 it surpassed its Japanese rival Sony for the first time in the history and become the world twentieths largest and popular brand as evaluated by Interbrand. In 2007 the firm became the largest mobile phone producer and overtake Motorola for the first time. In 2009 however, performance was revenues of $\$ 117.4$ billion and overtaken Hawlett-Packard and became the world largest technology firm measured by sales. Nonetheless, the firm has been succeeded to operate firth generation technology also the exynos processor installed in S4 used around the world. Generally, due to market expansion in China and India the firm has achieved the record earnings of third quarter of 2013 of about $\$ 9.4$ as operating profits this was boosted by memory chip selling.

\section{Samsung Electronics Structure}

Figure 1: Samsung Electronics Organisation

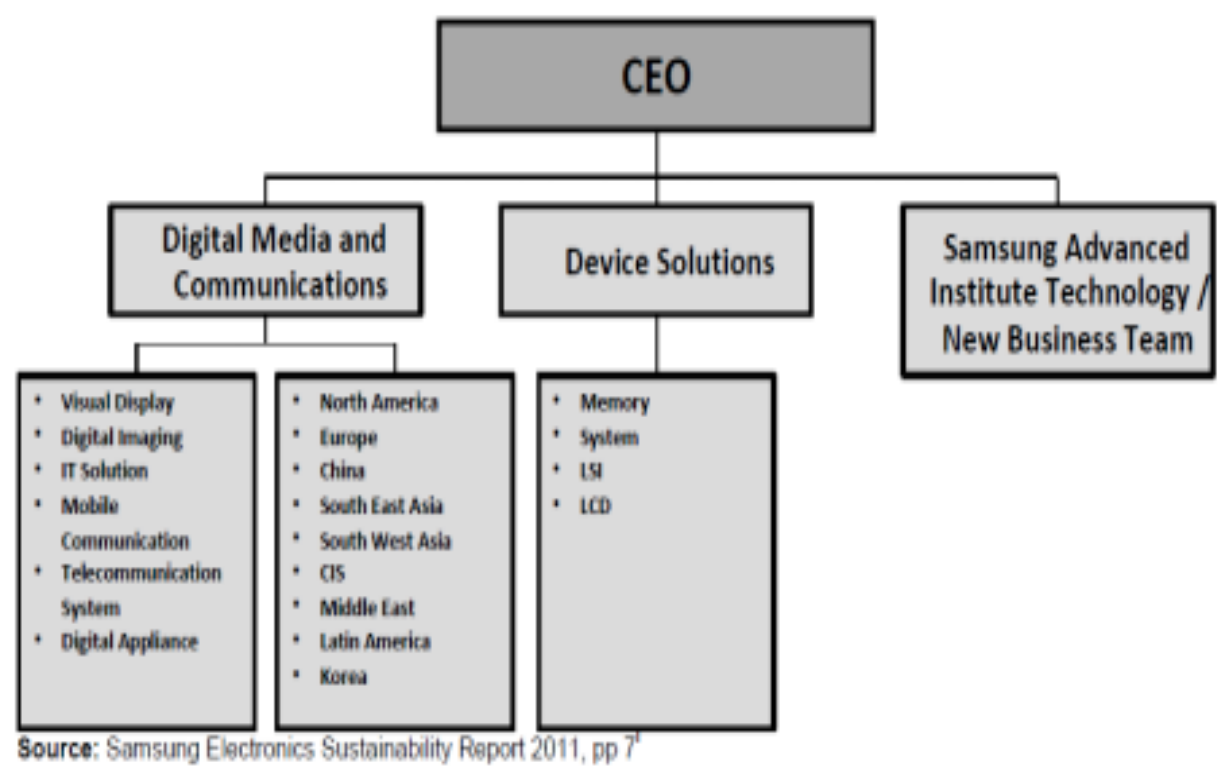

Sources: adopted from www.google.com ( 2015)

\section{STRATEGIC DIRECTION}

Basically, strategic direction is an important management tool to many managers in the world. It highlights the most important phenomena upon which the organization is undertaking Jonhson \& Scholes (2002). Indeed, it defines the strategic intent of the organization and also the way how the initiation of change can be managed in order to happen. On the other hand, strategic direction also includes learning from other global competitors, managing information 
technology as well as protecting technological lead. Moreover, strategic direction also helps individual firm to procuring, organizing, utilizing competitive information as well as the recruiting, motivating by keeping people needed in the business and using manufacturing as a strategic weapon. Arguably, Samsung electronics has been extraordinarily caring in terms of its strategic direction recently and that has been the key to its success. The firm recruit a very competent people to work and drive the firm to achieve its intended objectives. However, the firm has to do more in terms of employee's retention as this will help the firm to compete effectively in the market.

\section{Mission Statement}

\section{MISSION, VISION \& CORE VALUES}

"To inspire the world with innovative technologies, products, design that enrich people's lives and contribute to a socially responsible, sustain future"

Arguably, the company seems to revolves within it mission statement in terms of its innovating thinking currently known as the best innovative organization in the world. Indeed, it managed to provide variety of products to enrich its customer and fulfill their expectation and needs. However, the firm has to do more in terms of social responsibility as well as the future sustainability to the customers and society at large.

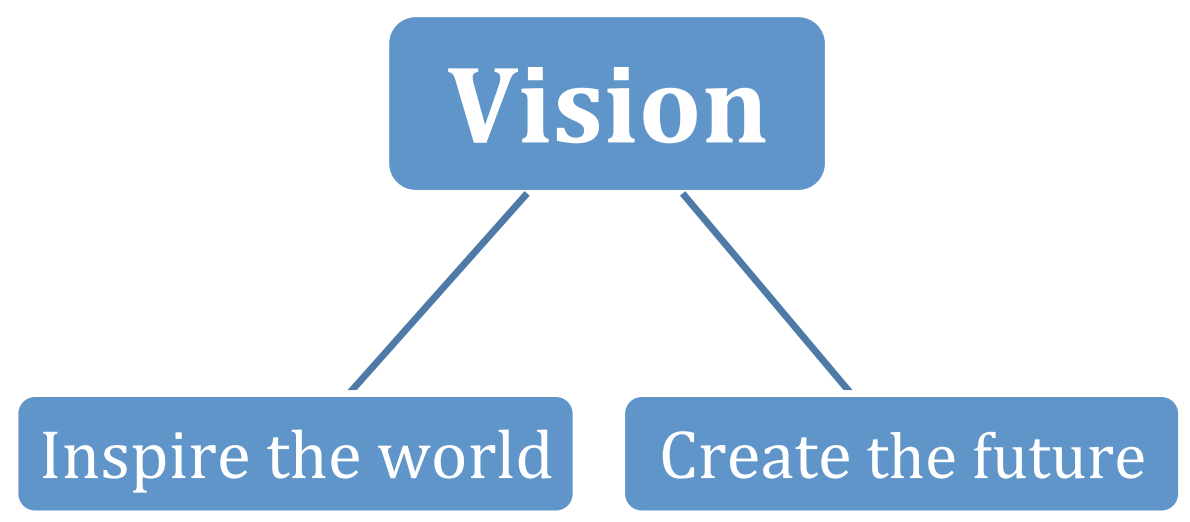

Goals and Objectives 1.4

Indeed, the company has managed to categorize its objectives as describe below: Qualitative goals;

$>$ USD 400 Billion in sales year 2020.

> Predominantly no. 1 in global IT industry \& Global top 5.

$>$ Quantitative goals;

$>$ To be innovative company

$>$ Creative leader in building new market

$>$ Global enterprise that attracts world's best talents

More significantly, to achieve these potential objectives however, the firm must have sufficient resources that will enable it to perform better in the global arena and gain competitive advantages. The resources capability however, must be taken into account based on human capital that play significant role in the business process such as marketing, finance, operation and indeed in management. If these matter have been achieved however, the firm will be able to achieve it intended goals and objectives. 


\section{NATURE OF COMPETITION}

According to Michael Porters (1980s), industrial analysis can be done based on the following framework.

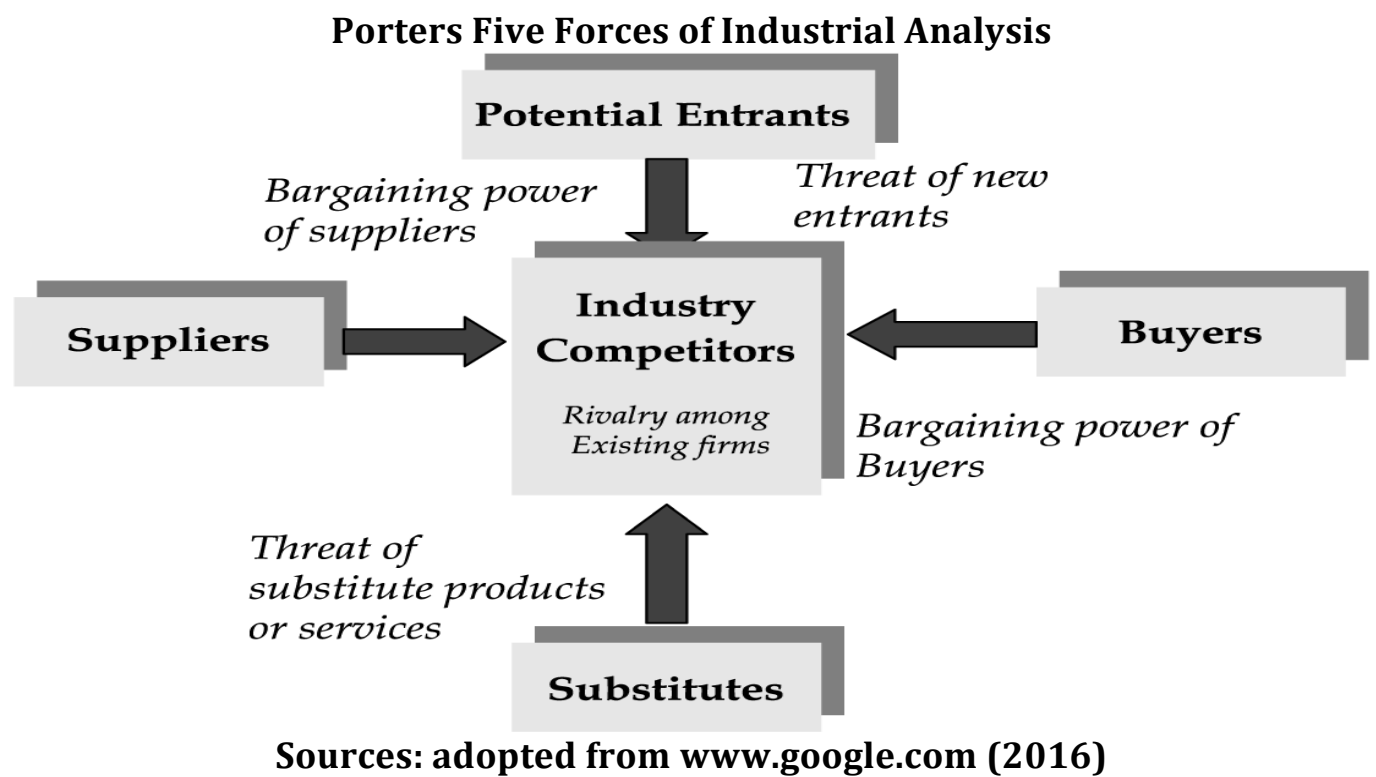

Industry competitor: is high due to existence of players of such as Apple, Nokia and Motorola which use several attack options on Samsung Electronics.

Potential entrants: is bit lower due to the level of resources and capability required to enter in the industry.

Bargaining power of suppliers: is lower due to the horizontal and vertical integration strategy employed by the firm upon which most of the required outputs are available within the company and reduce the level of dependence on other supplies.

Bargaining power of buyers: the is high as the customer may well be able to switch from one brand to another, so they pose great threat, and therefore the firm should use its resources to retain the customer based on Customer Relation Management.

Threats of substitute products and services: is high as customer may substitute their products to sort out their problem either by switching to other company products to deal with existing requirements.

Basically, many experts such as marketing analysts, managing directors, management consultants, financial directors, company director as well as chief executive and their advisors agrees that there are four important types of competition that one should put into account when analysing a particular industry, Porters (2004). Pure Competition however has been characterized by many players in which everyone is free to sell their services and product, therefore the market is free for everyone to enter and perform a business. Imperfect competition however, there are a number of players but differs in terms of their quality, durability as well as the usage of their product and services. These variations therefore, help a certain firm to achieve the market share and eventually competitive advantage. Oligopoly however, is another types of competition where there are few players who control the market normally is due to barrier to entry they create including patent rights as well as the lack of threshold capability of other players. Monopoly type of competition is the last type of competition where there is no competition at all and the whole market is controlled by one firm. 
Arguably, Samsung Electronics is currently operating within oligopoly nature of competition where it seem as there are some few players which control the market and indeed the firm have created potential barriers for other players to inter in the market particularly in smart phones where many of them fail to compete due to poor resources in terms of people, finance and technology. However, some may argue that the firm is operating under imperfect completion and it only achieved its competitive advantages due to differentiation in quality, usage, durability and sophisticated technology used in their products which helps to overtake other players such as Nokia, Apple and Motorola and HTC. Therefore, the quick these competitors strengthen their threshold resources the sooner will overtake the Samsung Electronics. Therefore, Samsung Electronics has to do more to make sure that the firm competitive advantages are not ruined by other competitors by taking the following steps:

* Causal ambiguity, this approach requires that the firm design its organization in the way that other competitors do not know which area the organization has its strength.

* Complexity, basically under this approach the firm may design it value chain in a very complex way in which the competitors may remain clueless on the strength of the firm and ultimately fail to compete or imitate what the firm is doing and eventually do not know what is the secret behind it success.

* Cultural embedded, under this technique the manner upon which the culture has been embedded within the organization confuse the competitors. This is starting from where the products are manufactured or assembled, supplied, and reached to the customers has to be unique which then become extremely difficult for others to imitate.

\section{COMPETITIVE POSITIONING}

Potentially, the company may well position itself according to the strengths and weakness it has in the particular industry, Johnson \& Scholes (2002).

Samsung Electronics SWOT Analysis

\begin{tabular}{|c|c|}
\hline $\begin{array}{l}\text { Strength } \\
\text { High market shares and sales } \\
\text { Strong financial performance } \\
\text { Stability of sources of finance } \\
\text { Creativity, innovation and technology } \\
\text { Strong marketing skills. } \\
\text { Excellent coordination, monitoring and } \\
\text { evaluation. }\end{array}$ & $\begin{array}{l}\text { Weaknesses } \\
\text { Patent right breaching } \\
\text { Brand image is weak compared to apple. } \\
\text { Less consideration on new products. }\end{array}$ \\
\hline $\begin{array}{l}\text { Opportunities } \\
\text { Political encouragement and will } \\
\text { Excellent community response } \\
\text { Product development } \\
\text { Market development } \\
\text { Supports from the donor and advocacy. }\end{array}$ & $\begin{array}{l}\text { Threats } \\
\text { Strong competition } \\
\text { Existence of detrimental external policies } \\
\text { Economic slow down } \\
\text { Availability of substitute products } \\
\text { Political instability such as war. }\end{array}$ \\
\hline
\end{tabular}

Sources: (Author, 2016)

Michael Porter (1980s) from Harvard Business School however, developed with the model which may well help the organization to position itself in the market it operates. He developed model which is known as Generic Strategic which consists three important positioning options such as Differentiation, Cost leadership and Focus. Therefore, the company may potentially opt to differentiate itself in terms of products or services and being unique at that particular market. Therefore, that uniqueness will help the organization to gain competitive advantage. 
Also, the firm may adapt cost leadership by exploiting the organization resources and manufacture quality products using very low cost and selling it in the very reasonable cost. Indeed, the firm may also position itself based on focus positioning strategy by focusing on certain market segment which it thinks that it may well compete effectively sometimes known as Niche Market. On the other hand, some experts developed a Hybrid strategy which basically look at the combination of the above strategies depends on the organization resources and objectives

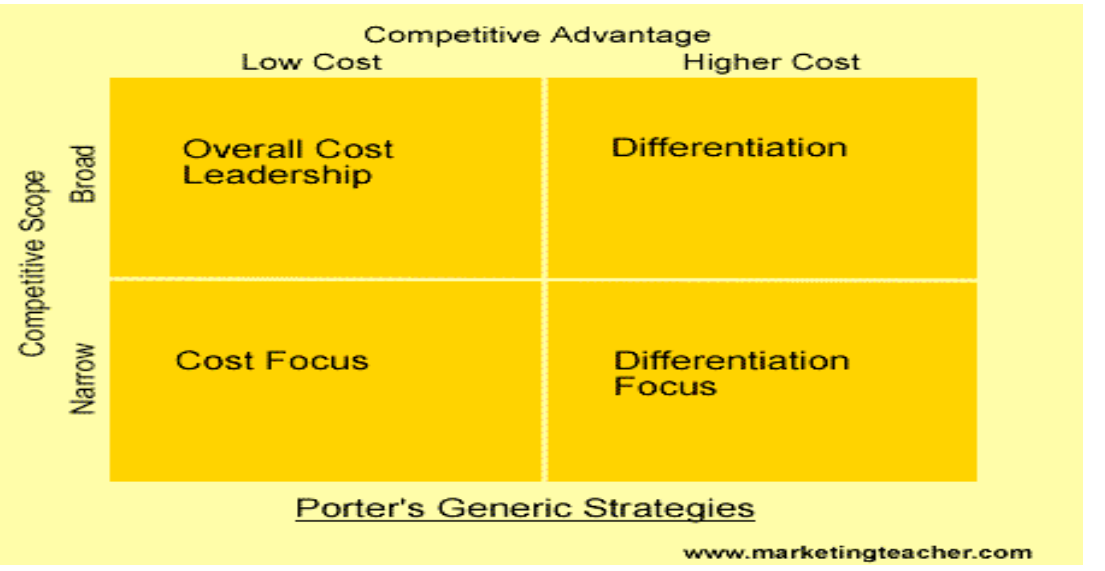

More significantly, Samsung Electronics tends arguably to adapt hybrid positioning strategy based on differentiation and cost leadership. This happens when the firm launch new mobile phone for a particular market in order that the customer should also buy the product in affordable price, this was Samsung Galaxy S and Y which many lower income customers may afford. Indeed, the firm also differentiated itself based on technology through which the firm develop its own software and use it to its mobile phones and also supply them to other companies such as A7 processor supplied to Apple. The question whether this strategy is good enough for the company remains crucial especially due to dynamic nature of the world and indeed in technology which basically keep changing so faster. Therefore, the firm must review this strategy periodically to avoid any potential future pitfall of the firm particularly in terms of low cost as to some customers low price is not criteria to purchase their products. Then, it is very crucial to manage it to avoid being branded as cheap company, and create image which many customers think there is low quality. Moreover, the firm, if it wishes to pursue its low cost strategy must adapt economy of scale, and also concentrate on lean manufacturing to avoid being stuck at the middle.

\section{Drivers for Change}

Basically, any organization must put much emphasis to study and predict the possible changes that may potentially impact the organization in one side or another (Johnson \& Sholes, 2006). In this respect therefore, in this uncertainty world many business executives and analysts worrying on which change might occur and cause considerable damage to the firm. However, based on some research, there are some important changes that have been identified which could provide detrimental impact to the firm (Johnson 2002). The change based on the consumers preferences, as many consumers buying behaviour will be determined and dictated by the how it can serve and fit for a purpose rather than the price. Therefore, Samsung electronics must learn and predict the unarticulated market demand and quickly translate the customer preferences into product or services delivery. Moreover, the energy cost is going up therefore Samsung should invest in energy efficiency to position itself in its operational structure. As not enough, tax policy may well impact the organization therefore the firm should capitalize its process in terms of finance. Moreover, innovation also remain the crucial change that may potentially impact therefore Samsung may need to be more creative to innovate 
technology which could suit the organization product and better position itself in the future. Nonetheless, the vertical integration also remain the most important change as many organization tend to vertically integrate their operations this helps to reduce dependency on the suppliers this strategy already adopted by Samsung which provide synergy to the customer. Indeed, the industry shift also create competitive shift, where now Samsung Electronics should think of new techniques to compete with new competitors and not traditional ones by reassessing its core competences and use scenario planning to identify new competitors. On top of that, increasing of information due to sophisticated information technology has been big change which may impact the firm as the Chief Executive may be confused and make poor decision. So then, the firm should collect, cultivate and exploit asymmetries in high quality information and indeed build strong and robust information filter rely on the unbiased judgement and enough experience. Likewise, the market reward for long term strategic focus for investors rather than buyback to boost share price, therefore firm must put concentration in longer terms corporate strategy. Nevertheless, the economic down turn may potentially affect the firm, based on its suppliers, partners and customers; therefore the firm should assess the environment. Lastly, the war for the talent employees, basically, study suggests that $25 \%$ of the higher potential talent address their interest of leaving their company. Therefore, the company should develop a high potential employees planning and encourage the potential competent worker to win the future talent battle.

\section{Strategic Option for Growth}

More remarkably, strategic growth remains as a very crucial issue in the business and organizations spends more time and money to develop strategies that would help the firm to grow ( Kotler 1999). The most common model used to cultivate strategies is Unsoff Matrix Model. In relation to Samsung Electronics this model can be analyzed as following.

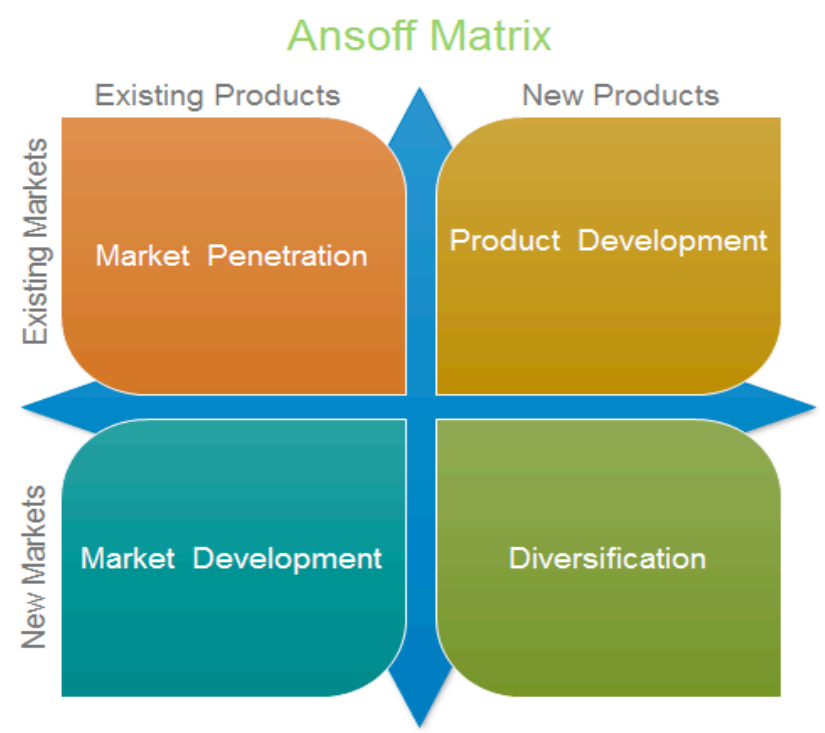

Sources: adopted from www.google.com (Google, 2015)

Market Penetration, basically the firm aimed to achieve growth through existing products with the existing market segments and indeed seeks to increase its market share. Samsung Electronics however, the firm managed to increase market share by launching several products in the existing market. Classic examples in the introduction of Samsung Galaxy S3 and S4 which potentially help the firm to increase the market share.

Market Development, indeed under this approach the company tends to use its existing product to develop new market and ultimately increase market share. Samsung Electronics 
however, managed to develop its market using its existing product when it launches several products by targeting Chinese and Indians market. Therefore, the introductions of Samsung Galaxy $\mathrm{S}$ and $\mathrm{Y}$ in those markets helped the firm to increase its market share and sales volume.

Product Development, the firm is basically, develop new product and target to its existing market so as it may increase its market share. In relation to Samsung however, the firm was able to develop Samsung Galaxy Note 1, 2 and 3 to its customers. These products however, helped the firm to gain high market share and gain competitive advantage. However, this strategy need close reassessment to avoid repetition of the product and damage the customer expectation.

Diversification, nonetheless, the firm may grow itself by through diversifying in new products with new market. However, Samsung was able to diversify based on related diversification as well as he unrelated ones such as pharmaceutical industry. Arguably, diversification may also need to be considered strategically as too much conglomeration may lead to ineffective and inefficiency and may lose focus of the firm.

\section{Boston Consulting Group Matrix (BCG Matrix)}

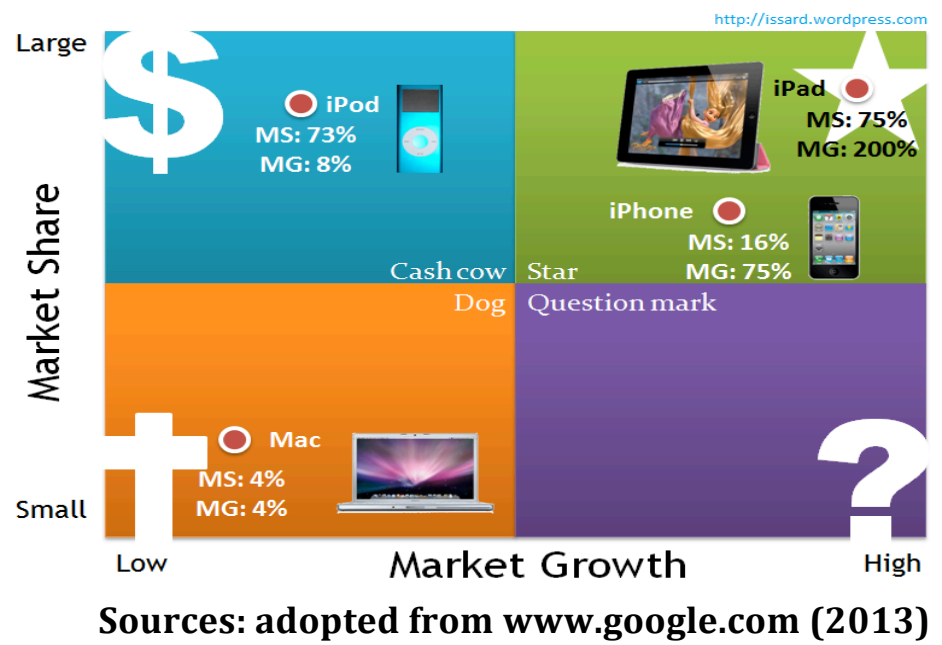

Basically, the board of directors will potentially not approve any funds to be used in the business if there is no sufficient information on which product will provide a high return to firm and help in both market share and market growth. Therefore, the GCG Model will help the firm to identify which product give high return and how it can invest on that and using which strategy. In Samsung Electronics however, there are several products upon which the firm should be extremely careful to identify and focus on them. Arguably, the firm currently has several product lines which basically need not much attention. Therefore, the firm should not only diversify but look at the need and return related to that diversification, by building market share strategy of holding ( Star Products) by investing on the high return products, using holding strategy by executing on the strategy, harvesting ( Cash Cow) strategy by reducing the investment on that products such as promotion, advertisement, and also the divest strategy (Dogs) require to just abandon or eliminate the products which potentially have no interest with the business. Samsung electronics is arguably trying its best to focus but the writer believes that it is not good enough, then the firm has to do more in terms of focusing on which products gives best return based on the market share and growth. 


\section{Organization for Success}

Indeed, there are several reasons upon which contributed many organizations to go internationally. These can be illustrated as following here below:

\section{REASONS FOR GOING GLOBAL}

- Increasing Market share by increasing sales

- Cost reduction based on labour and technology

- Maximizing profits and assets by acquisition

- Seeking and increasing, knowledge, technology and innovation

- Long term and short term security of the business.

- Market saturation due to its smallest size at home

- The nature of competition at home market such as hyper competition

Sources (Author 2015)

\section{Criteria Selected for Global Expansion}

More importantly, according to Richard Lynch (2006) there are potential global strategies through which the company should bear in mind before going abroad. Indeed, the most crucial issue here is the resources and capabilities consideration before global expansion. These include:

The Company Resources and Capabilities

\begin{tabular}{|c|c|}
\hline $\begin{array}{l}\text { Built in the company's resources and } \\
\text { capabilities in its home market. }\end{array}$ & $\begin{array}{l}\text { - Differentiated products such as } \\
\text { L'OREAL patented cosmetics products. } \\
\text { - Low cost products such as Chinese } \\
\text { manufacturing low labour cost with low } \\
\text { currency advantage. } \\
\text { - Dominant market share such as } \\
\text { Microsoft Company. } \\
\text { - High performance products such as } \\
\text { Japanese bullet trains. } \\
\text { - High quality and reliability such as } \\
\text { that of Mercedes and Honda car } \\
\text { products. } \\
\text { - Superior service level such as that } \\
\text { produced by GUCCI and DHL. } \\
\text { Network and support services such as } \\
\text { that produced by Apple. } \\
\text { - Core competences such as that } \\
\text { produced by Canon in its optical lenses. } \\
\text { Branding such as that of NESTEL in } \\
\text { its ice cream products. } \\
\text { The reputation of the company such } \\
\text { as that of Nike in its sportswear. } \\
\text { Knowledge such as that of produced by } \\
\text { NORVATIS pharmaceutical company. } \\
\text { Leadership and Human Resources } \\
\text { expertise such as that produced by } \\
\text { McDonald. }\end{array}$ \\
\hline
\end{tabular}


Arguably, Samsung Electronics has been able to full fill its resources and capabilities particularly based on the technology which recently help the firm to be branded as the most successful technological industry in the globe. However, more efforts must be made in its process to remain consistent in it performance in the market. On the other hand, the company used several methods to in its global expansion by using the exporting, acquisition as well as joint venture. Also proper assessment required when using these entry methods to avoid unnecessary troubles to reduce the risk that could be incurred in this turbulent globe.

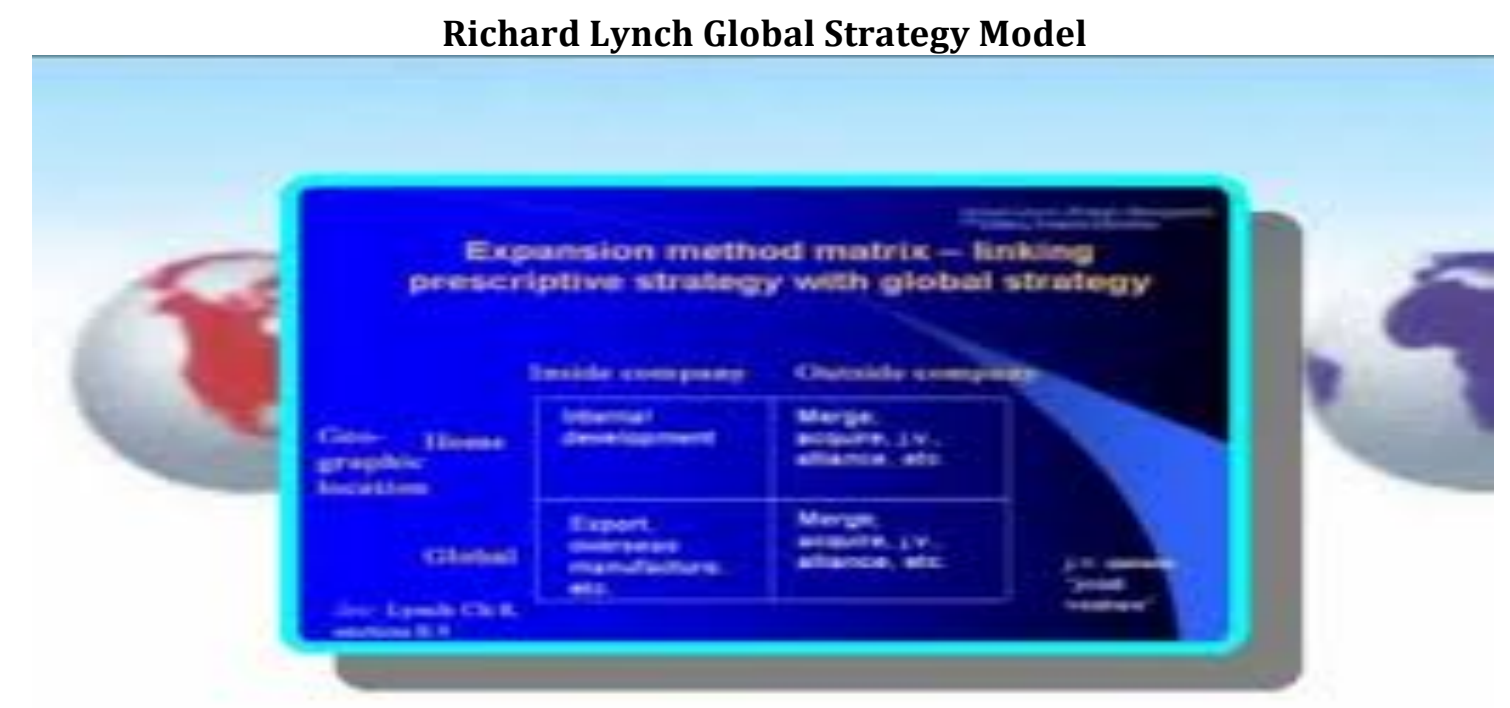

\section{Sources: adopted from www.google.com (2016)}

On the hand, it is worth noting for the organization which seeks to expand its market globally by considering the Michael Porter Diamond Model of that particular country in which the organization is operating. However, arguably Samsung Electronics was able to consider these factors by locating it activities in the country which fit in Porter Diamond model such as USA and China. However, the firm should also consider it expansion in the other countries which recently made stunning performance such as the BRICs nations.

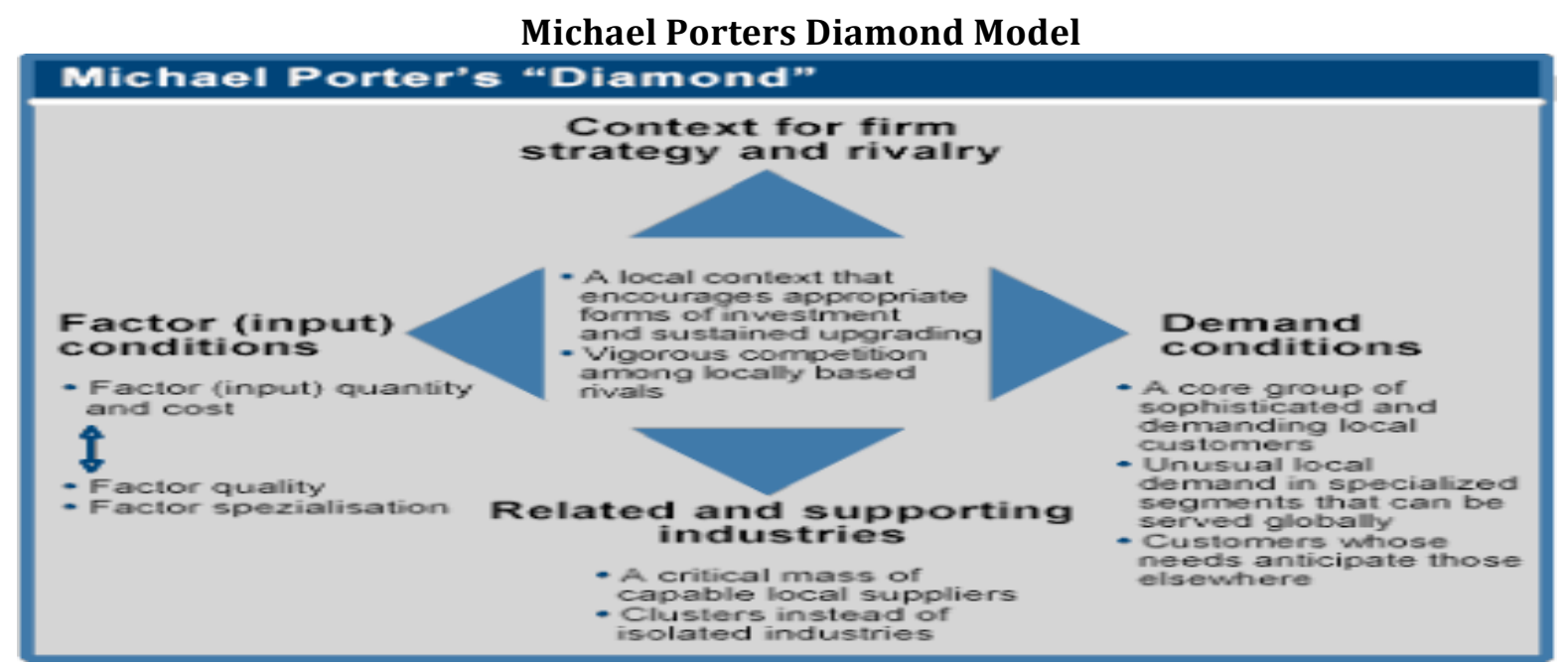

Source: adopted from www.google.com ( 2016) 


\section{Evaluation of the Criteria}

More remarkably, Johnson \& Scholes (2006) admitted that, the firm required evaluating its strategies based on the time scale by looking it in terms of Suitability, Acceptability and Feasibility (SAF)

\begin{tabular}{|c|c|}
\hline \multicolumn{2}{|c|}{ Criteria for Strategy Evaluation } \\
\hline Suitability & $\begin{array}{l}\text { - Rational of overall strategy } \\
\text { - High economy of a scale }\end{array}$ \\
\hline Acceptability & $\begin{array}{l}\text { - Positive response from the } \\
\text { stakeholders such as shareholders, } \\
\text { customer, employees, supplier, etc. }\end{array}$ \\
\hline Feasibility & $\begin{array}{l}\text { - Human capital capability to supports } \\
\text { - Financial capability to support the } \\
\text { strategy } \\
\text { - Marketing capability to support the } \\
\text { strategy. } \\
\text { - Strong information system } \\
\text { management. }\end{array}$ \\
\hline
\end{tabular}

Sources (author, 2016)

Arguably, Samsung electronics strategy seems to be potentially working at the moment. For example based on suitability the current strategy seems to suit with the organization based on the economy of scale and help the firm to gain competitive advantage against other competitors. Moreover, the current strategy seems acceptable by the stakeholders such as the customers and the supplies and shareholders. On the hand, the strategy sounds feasible due to the current performance of the organization produced due to availability of required resources such as human capital, marketing, finance and technology. However, the firm has to do more assessment to not only maintain consistency but also to improve its resources and capability so as to reduce the risk and attain its competitive advantages Johnson \& Scholes (2002).

\section{Implementation and Control}

Basically, during the implementation of the company strategy management guru developed model that can help to achieve the organization goals and objectives. The model was defined designed to into two groups Hard S's the first three and Soft S's last four.

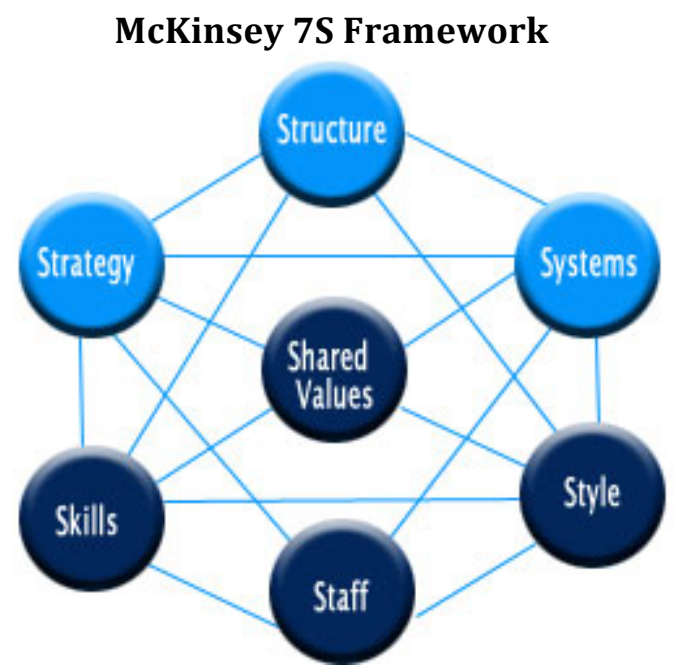

Source: adopted from www.google.com (2016) 


\section{Resources Implications and Change required 4.1}

Indeed, there implementing a certain strategy resources are required these include human resources, finance, strong marketing skills as well as innovation, creativity and technology. Therefore, Samsung Electronics must have sufficient resources to implements the strategy in global business. Indeed, Balogun \& Hailey (1999) admitted that, there are some changes that may occur based on the need which will be discussed below:

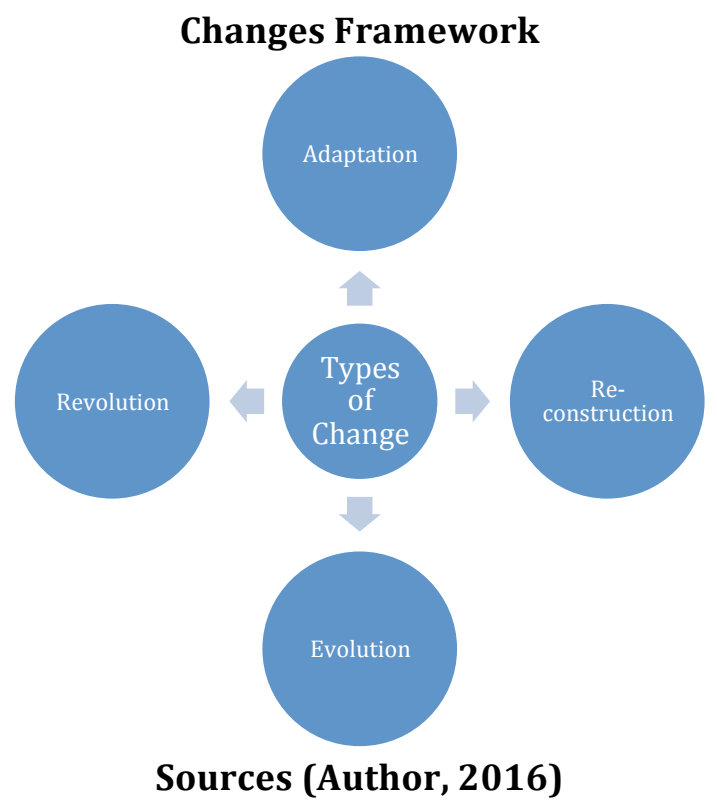

Adaptation: basically, this type of change involves the incremental or slow changes upon which there is no need for the corporate cultures change to be undertaken by the organization. Samsung Electronics can adapt due to the current requirements.

Reconstruction: basically, this type of change involves potential rapid strategic change but there is no need for corporate cultures change. In relation to Samsung the firm the change can be applied based on products development of focus on the best return products.

Evolution: this type of change involves the incremental change but do not involve the corporate culture changes. This type of change may be applied but it is not necessary for this particular time.

Revolution: Indeed, this change involves not only the rapid strategic changes but also the corporate cultures change.

\section{CONTROL PERFORMANCE MEASURES}

More significantly, Samsung electronics employed different control measures in different parts of the organization such as that of corporate, functional and operational level (Johnson \& Scholes 2006). However, to organize for success the firm may employ organization configurations based process, structure and relations (Lynch 2006). Indeed, to enable more success for the firm, more control required in terms of information, people, finance and technology. These may likely be possible by adapting strategy such as "Turnaround Strategy" which could help the firm to change the failure strategy without affecting the organization culture and it also ensure that the benefit of new strategy is well understood and accepted by all stakeholders especially employees, shareholders and customers.

\section{RECOMMENDATIONS}

Basically, the firm at the moment seems to have better position in the global business. However, there are a lot of measures need to be taken into consideration; 
Relying on the products development whereby not every consumer would like to see new products which serves similar needs and wants, therefore differentiation is the most important issue to be considered.

* Not all customers purchase product based on the low price but based on the quality and value of the product and sometimes cheap products brings poor image to the firm.

* Conglomeration based on horizontal and vertical integration may sometimes lead to less efficiency and effectiveness of the firm especially if it is not well managed.

* Based on the product portfolio the firm must concentrate on the products that bring high return to the organization and eliminate those which provide less or nothing to the financial health of the organization.

\section{References and Bibliographies}

Bawdin G et al (2006), Event Mannagemant, (2ndedn),Elsevier, London United Kingdom, pp 95,117

Johnson J \& Scholes K (2002), Exploring Corporate Strategies (Case \& Text), 6th end, Prentice Hall, London, United Kingdom, $\mathrm{p} 12$.

Jonhson G et al (2008) Exploring Corporate Strategy, (8th edn), Prentice Hall, London, United Kingdom, pp 49, 215.

Kay J (2005), Foundation of Corpoarate Strategy (The Most Important Contribution to Business Thinking In Decade), Oxford University Press, London United Kingdom, PP 211, 101,

Lynch R (2006), Corporate Strategy, (4th edn), Prentice Hall \& Pearson Education, London, United Kingdom, pp, $2,76,445$.

Sookun M, (2011), Environmental Analysis, London School of Commerce, London, United Kingdom.

Mintberg H et al (2009), Strategy Safari, (2nd edn), Prentice Hall, London, United Kingdom, 86.

Niale B \& Pike R ( 2005), Corporte Finance \& Investiment ( Decisions \& Strategies), 5th edn, Prentice Hall, London, United Kingdom, pp 123, 178.174.

Pottabathni G, (2009), Wall-Mart Strategy, Case Study. Available on: http:www.articlebase.com/strategic-planning article (accessed on 2nd Dec 2013).

Bronzite M, (2000), System Development (Strategic Frame Work), Springer Ltd, London, United Kingdom.

http//www,bized.com (accessed on 10th Dec. 2015).

http/www/googlescholars.com.retrieved on January, 2016.

Intrernet Center For Management And Business Administration, (2009-2010), Porters Competitive Strategy, Blog, Available From http, www, QuickMBA.com accessed on 2nd Dec.2013.

Meek et al (2002) Strategic Marketing Management (Planning \& Control, Elsevier Science Limited, Italy.

Mursay I, (2006), the Franchizing Handbook, Kogan Page Limited, London, United Kingdom.

Wall-Mart (2009), Retail Colleague Handbook, London, United Kingdom.

Robson W, (1997), Strategic Management Information System, 2nd edn, Prentice Hall, London, United Kingdom,

Robert D et al, (2006), Strategic Information Management, 3rd edn, Elsevier Butterwoth Hainemann, London, United Kingdom.

Lynch R, (2012) Strategic Management, 6th edn, Peason education, London, United Kingdom.

Http.www.samsung electronics.com, retrieved 0n, 9th Dec, 2013.

Porters M, (2004) Competitive Strategy, Techniques for Analysing Industry and Competitors, New York, United State of America.

Balogun J \& Hailey H (1999), Exploring Strategic Change, Prentice Hall, London, United Kingdom. 
Kotler P, (1999), Kotler in Marketing (How to create, Win and Dominant Market), Free Press, Unitet States.

Stickland, T. P. \&. G., 2012. Crafting and Executing Strategy (Concepts and Cases). New York: McGraw-Hill.

Keller, P. K. \&. K. L., 2009. Marketing Management. 13 ed. London: Peason. United Kingdom

Lynch, R., 2003. Corporate Strategy. 3rd ed. Essex: Prentice Hall. United Kingdom

Robert Bugelman, C. C. S. W. 2004. Strategic Management of Technology and Innovation. 4th Ed. New York: McGrow Hill.

Johnson \& Scholes, 2012. Exploring Corporate Strategy. 9th ed. London: Peason Education Limited. 